\title{
Мультимедийный контент в онлайн-СМИ Швейцарии
}

Мария Зайцева

В статье рассматриваются онлайн-медиа

надрегиональных и локальных изданий Швейцарии, а также мультимедийный контент, публикуемый ими. Анализируется, как типология издания, его бизнес-модель и запросы аудитории влияют на использование современными швейцарскими СМИ конвергентных элементов: текста, фотографии, аудио- и видеоконтента, инфографики, тайм-лайна и т.д. Автор делает вывод, что, исходя из специфики работы, редакционных возможностей и особенностей медиапотребления собственной аудитории, редакции самостоятельно выбирают подходящие мультимедийные элементы, вырабатывая оптимальные форматы медиатекстов и напрямую вступая в коммуникацию с пользователями.

Ключевые слова: мультимедийный контент, конвергенция, интернет-СМИ, новые медиа и медиатекст, Швейцария.
(C) Зайцева Мария Геннадьевна аспирантка кафедры зарубежной журналистики и литературы факультета журналистики МГУ имени М.В. Ломоносова (г. Москва, Россия), marimariorse@mail.ru

\section{Введение}

Цифровизация изменила структуру современного медиарынка, и Интернет стал ключевым источником информации. Онлайн-платформа позволила выйти на рынок независимым СМИ, внедрить новые способы монетизации и интегрировать разные формы контента, создавая качественные, интерактивные и конвергентные медиатексты. Этому способствовал и рост количества устройств, способных воспроизводить медиаконтент, помимо компьютеров в число таких устройств входят смартфоны, планшетные компьютеры, цифровые телевизоры (Лукина (ред.), 2013: 15).

Вопросы влияния новых технологических возможностей на работу современных редакций затрагивали многие российские и зарубежные авторы. Одним из основных предметов изучения в цифровом сегменте медиа исследователи называют конвергенцию (Latzer, 2013; Вырковский, Галкина, Колесниченко, Образцова и др., 2017). Ее характеризуют как слияние различных по своей природе СМИ - сточки зрения организационной структуры и технологии передачи взаимосвязанной, консолидированной информации (Хелемендик, 2013: 107). Объединение текстовых, визуальных и аудиальных компонентов привело к появлению нового медиатекста. «Практика 
показывает глубокую конвергенцию всех коммуникативных технологий, трансформацию стратегий и тактик создания, каналов распространения и механизмов восприятия контента», - считает М.А. Пильгун (2015: 195). Особенно заметно возрастание роли визуального контента, вербальные компоненты медиатекста дополняются фото- и видеорядом, элементами дизайна и инфографики, которые также несут важную смысловую нагрузку. Популярности визуального контента способствовало распространение новых информационных платформ - социальных сетей, стриминговых сервисов. Кроме того, актуальными остаются вопросы жанрового разнообразия в онлайн-медиа (Калмыков, Коханова, 2017) и медиапотребления (Уланова, 2017; Вьюгина, 2017).

Онлайн-медиа по-разному используют возможности цифровой платформы - тип издания, бизнес-модель и запросы аудитории определяют его работу с мультимедийным контентом. Цель данного исследования - проанализировать онлайн-медиа и мультимедийный контент, публикуемый ими, и определить, как типология издания, его трафик и аудитория влияют на использование в публикациях конвергентных элементов. В качестве объекта анализа были выбраны немецкоязычные СМИ Швейцарии: Neue Zürcher Zeitung, Basler Zeitung, Tages Anzeiger и Südostschweiz.

Медиасистема этой страны представляет особый интерес: четыре национальных языка, 26 кантонов, в которых насчитывается около трех тысяч локальных сообществ, обусловили локализацию медиарынка. Медиасистему Швейцарии относят к «демократически-корпоратистской модели» (Hallin, Manchini, 2004), она характеризуется традицией «партийной прессы», восходящей к XX столетию, и активной ролью государства в продвижении средств массовой информации, что хорошо заметно на примере функционирующей системы общественного вещания. На сегодняшний день швейцарский медиарынок один из самых насыщенных в мире, в стране с населением в восемь млн человек выпускается 309 изданий с общим тиражом в 7 млн экз. ${ }^{1}$

Особенности медиасистемы Швейцарии были описаны исследователями К. Имхофом (2006), У. Вагнер и Х. Тойнтер (2006), Р. Блумом (2014) и другими, в России национальный медиарынок Швейцарии исследует Т.С. Якова (2017). Ежегодно Цюрихский университет выпускает отчет Qualität der Medien, где описываются последние тенденции рынка, публикуется актуальная статистика и определяются основные направления развития. Также при университете работает организация Media Change \& Innovation Division, сотрудники которой исследуют взаимосвязь медиа с социальными и политическими вопросами швейцарского общества. Нужно отметить, что статистические данные рынка находятся в открытом доступе, портал NET-Metrix публикует показатели трафика всех онлайнмедиа, отображая общее количество посещений сайта, количество уникальных посетителей, среднее время, которые читатели проводят на сайтах.

Тенденция к цифровизации хорошо заметна на примере швейцарских медиа. За последние годы значительная часть аудитории традиционных средств массовой информации (в основном абонементных газет и общественного радио) переориентировалась на Интернет (Якова, 2013). Исследования показывают, что онлайн-СМИ становятся приоритетным источником информации для швейцарцев: 83\% населения за новостным контентом обращается к онлайн-источникам, 62\% - к телевидению, 49\% - к печатным СМИ². Самыми посещаемыми сайтами остаются поисковики (google. ch, bluewin.ch) и социальные сети (facebook. com, youtube.com). Кроме того, статистика показывает, что более половины пользователей Facebook в Швейцарии используют 
социальную сеть для получения новостного контента. Наиболее популярными цифровыми медиа остаются 20min.ch, srf.ch, blick. ch, tagesanzeiger.ch, nzz.ch.

Цюрихский университет определил основные типы онлайн-медиа, распространенные сегодня в стране: новостные сайты, подписные издания, бульварные онлайнСМИ, бесплатные онлайн-СМИ, онлайнжурналы, порталы, порталы провайдеров услуг связи, общественные радиостанции, частные радиостанцииз. Подписные издания в Швейцарии являются наиболее значимыми с точки зрения производства качественного журналистского контента, в том числе для онлайн-платформ. Они сохраняют качество, поддерживая трафик, монетизируя контент через Paywall и рекламу.

\section{Методология исследования}

Качественная журналистика в Швейцарии традиционно пользуется высоким спросом, многочисленные общественнополитические СМИ до сих пор издаются большими тиражами и распространяются через подписку. Дигитализация позволила им выйти на новую платформу, расширить аудиторию, производить альтернативные типы контента. Медиа развиваются в зависимости от своих традиций, запросов аудитории, монетизации. Кто-то продолжает делать упор на текстовую составляющую, сохраняя консервативный публицистический стиль и делая акцент на качестве. Некоторые, напротив, пытаются привлечь новую аудиторию, работая над мультимедийным контентом. Использование мультимедийных элементов в материалах - хороший индикатор для оценки медиа. Проследив частоту применения таких элементов, можно выявить связь с типом издания, его аудиторией и бизнес-моделью.

В качестве эмпирических данных для контент-анализа были выбраны материалы немецкоязычных онлайн-СМИ Швейцарии.
Всего было рассмотрено четыре популярных медиа, трафик которых, согласно данным агентства NET-Metrix AG, превышает 400 тыс. уникальных посетителей в месяц (см. табл. 1)4. В выборку вошли надрегиональные и региональные издания: Neue Zürcher Zeitung, Basler Zeitung, Tages Anzeiger и Südostschweiz. Надрегиональные Neue Zürcher Zeitung и Tages Anzeiger, редакции которых располагаются в Цюрихе, на протяжении многих лет остаются ведущими качественными изданиями в стране. Basler Zeitung и Südostschweiz успешно работают в отдельных кантонах. Последнее, к примеру, издается в городе Кур (кантон Граубюнден), население которого не превышает 40 тыс. человек, но является заметным игроком на национальном рынке. Каждое из выбранных изданий использует PayWall, частично или полностью ограничивая доступ к контенту.

В рамках исследования было обозначено, как выбранные издания используют мультимедийные возможности цифровой платформы. Е.Л. Баранова (2017: 19) в пособии «Конвергентная журналистика: теория и практика» определила основные «средства», использующиеся для формирования медиатекста: аудио- и видеоконтент; инфографика; контент, собранный пользователями; блоги. Исследователи А.В. Вырковский, М.Ю. Галкина, А.В. Колесниченко, А.Ю. Образцова, С.А. Вартанов в статье «Мультимедийные элементы в современном медиатексте» (2017) предложили собственную классификацию: они выделили событийные фотографии, тематические фотографии, видео, тайм-лайны, интерактивные карты, инфографику, вставки из социальных сетей, рисунки и графику, фотоистории и фотогалереи, тесты. Опираясь на эти классификации и данные собственного анализа, нами было выделено 10 самостоятельных элементов: фото, иллюстрации, фотогалереи, видео- и аудиоконтент, инфографика, карты, таб- 
Таблица 1. Трафик онлайн-СМИ Швейцарии за январь 2019 г.

\begin{tabular}{|l|c|c|c|}
\hline \multicolumn{1}{|c|}{ Издание } & $\begin{array}{c}\text { Уникальные } \\
\text { посетители }\end{array}$ & Посещения & Показы страниц \\
\hline Neue Zürcher Zeitung & 3622000 & 15485607 & 39705719 \\
\hline Tages Anzeiger & 2075000 & 14682540 & 70306043 \\
\hline Basler Zeitung & 741000 & 4562645 & 23241283 \\
\hline Südostschweiz & 493000 & 1837399 & 5465088 \\
\hline
\end{tabular}

Источник: NET-Metrix AG, 2019. Режим доступа: https://netreport.net-metrix.ch/traffic/

лицы, пользовательский контент, тесты/ опросы.

Всего было проанализировано 11022 публикации, 9850 из них содержали те или иные мультимедийные элементы. Материалы публиковались на сайтах СМИ в период с 1 по 31 октября 2018 г. В ходе исследования были определены наиболее популярные мультимедийные форматы, используемые СМИ (см. табл. 2).

\section{Мультимедийные элементы в публикациях онлайн-медиа}

Изображения, галереи. Изображения остаются самой распространенной формой мультимедийного контента. Практически каждая статья, за исключением некоторых новостных заметок, сопровождается фотографиями. Кроме того, помимо пользовательского и заимствованного контента это единственный вид визуализации, не требующий дополнительных затрат на производство. Фоторедакторы и штатные фотографы - часть каждой редакции, а информационные агентства создают качественные фотобанки для быстрого поиска необходимых сюжетов.

Чаще других в качестве иллюстраций в материалах используют фотографии. Исследователи факультета журналистики МГУ имени М.В. Ломоносова выделяют следующие их категории - событийные и тематические. «Событийные фотографии, выполненные на мероприятии, о котором идет речь в тексте; тематические фотографии, не привязанные к событию картин- ки, иллюстрирующие текст» (Вырковский, Галкина, Колесниченко, Образцова и др., 2017). В выбранных для анализа изданиях событийные фотографии преобладают над тематическими: значительная часть текстов - новостные заметки, которые сопровождаются фотографиями событий. За октябрь 2018 г. Neue Zürcher Zeitung опубликовало 4235 материалов, их сопровождали 3154 фотографии. Südostschweiz выпускает материалы с интерактивными фотографиями, при наведении курсора на изображение на экране пользователя всплывают текстовые справки с дополнительной информацией. Также они используют фотосравнения - фоторамки до-после. Таких интерактивных фотографий за месяц было опубликовано 52 (всего фотографий 2654). Издание Neue Zürcher Zeitung выпустило только один материал с двумя интерактивными фотографиями, продемонстрировав разрушительные последствия урагана «Майкл» (на американский штат Флорида). СМИ также публикуют рисунки и карикатуры (Neue Zürcher Zeitung, к примеру, переняло традицию публикации таких изображений из печатной версии и продолжает ее на онлайн-платформе).

Часто издания обращаются и к галереям, размещая серии фотографий, отражающих одно событие. За тот же месяц Neue Zürcher Zeitung опубликовало 309 галерей, в каждой из которых было от 8 до 50 фотографий, Tages Anzeiger - 251 галереи, Basler Zeitung - 148. Галереи сопровождают материалы, посвященные последствиям природ- 
Таблица 2. Мультимедийные элементы в материалах швейцарских медиа, опубликованных в октябре 2018 г.

\begin{tabular}{|l|c|c|c|c|}
\hline Мультимедийный элемент & $\begin{array}{c}\text { Neue } \\
\text { Zürcher Zeitung }\end{array}$ & Tages Anzeiger & Basler Zeitung & Südostschweiz \\
\hline Фото & 3154 & 1163 & 2043 & 2654 \\
\hline Иллюстрации & 108 & 51 & 63 & 54 \\
\hline Видео & 249 & 544 & 730 & 69 \\
\hline Аудио & 5 & - & - & 11 \\
\hline Инфографика & 519 & 143 & 113 & 57 \\
\hline Таблицы & 36 & 9 & 6 & 2 \\
\hline Карты & 122 & 32 & 52 & 18 \\
\hline Пользовательский & 294 & 160 & 218 & 86 \\
\hline Гонтент & 309 & 251 & 148 & 148 \\
\hline Тесты/опроси & 7 & 29 & - & 8 \\
\hline Без ММ & 520 & 17 & 22 & 84 \\
\hline Всего материалов & 4235 & 1053 & 2889 & 2845 \\
\hline
\end{tabular}

ных катаклизмов, пожаров, публикаций о митингах, выставках, спортивных событиях. Это полезный для онлайн-СМИ ресурс, издания создают отдельные рубрики, которые выступают в качестве банка данных: материалы легко найти и использовать в текстах со схожей тематикой.

Инфографика, таблицы и карты. Инфографика - еще один распространенный вид мультимедийного контента (см. рис. 1). Ее задача - быстро и доступно передать большие объемы информации без потери смыслов. Она была распространена и в печатных изданиях, но цифровая платформа позволила сделать ее интерактивной. Инфографика дает возможность создать медиасообщение, наиболее удобное для восприятия пользователя (Пильгун, 2015). Быстро меняющаяся повестка сегодня требует оперативного поиска, отбора и структурирования больших объемов информации. Анализ показывает, что крупные редакции Neue Zürcher Zeitung и Tages Anzeiger - чаще производят и публикуют собственную инфографику нежели региональные. У них больше ресурсов для обработки и визуали- зации информации, а также инфоповодов, требующих дополнительной визуализации. Так, Südostschweiz за октябрь 2018 г. опубликовало всего 57 графиков, в то время как Neue Zürcher Zeitung - 517. На частоту использования этого вида контента влияют не только ресурсы издания, но и аудитория, затрагиваемые темы. К общественнополитической и экономической повестке Neue Zürcher Zeitung инфографика подходит хорошо, так как помогает быстро донести необходимую информацию: за октябрь 2018 г. издание опубликовало восемь самостоятельных материалов, включающих только этот тип контента.

Еще один распространенный мультимедийный формат, который используют редакции, - статичные и интерактивные карты. Передачу смыслов через карту часто называют маппингом. Это не линейный текст, а смысловое изображение, поэтому карты легко воспринимаются читателями. К ним обращаются при публикации материалов на общественно-политические темы, чтобы взглянуть на глобальную картину. В данном случае популярен интерактивный 


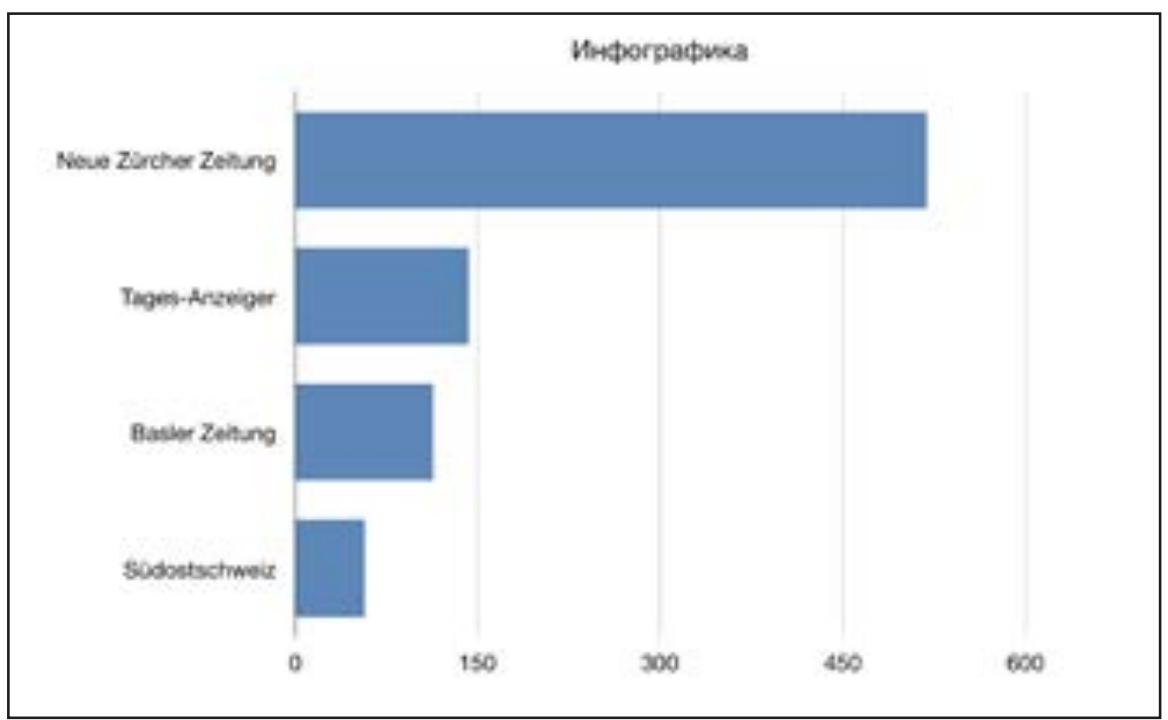

Рисунок 1. Использование изданиями инфографики в октябре 2018 г.

формат карт - при наведении курсора на изображение открываются всплывающие окна с дополнительной информацией. За октябрь 2018 г. Neue Zürcher Zeitung опубликовало 86 статичных и 6 интерактивных карт, Südostschweiz - 13 статичных и пять интерактивных.

Если изменения на фондовом рынке хорошо передаются с помощью инфографики, а политические конфликты - с помощью карт, то новости спорта могут быть представлены в таблицах. Neue Zürcher Zeitung часто обращается к этому формату, он легокдля восприятия и прост в производстве. Делать спортивные репортажи помогают также текстовые онлайн-трансляции (опыт редакции Basler Zeitung). Исторические события хорошо передаются тайм-лайнами, когда смыслы наносятся на временную линию. Tages Anzeiger периодически обращается к этому формату.

Видео- и аудиоконтент. О доминировании визуального контента в медиа говорит обилие видеоматериалов (см. рис. 2). Это самый популярный у поколений Ү и Z и быстрорастущий по объемам тип контен- та. Редакции все чаще обращаются к этому формату, привлекая аудиторию и выходя на новые платформы. Они публикуют ролики телерадиокомпании SRF и других телеканалов, агентства SDA ATS, видео со стриминговых сервисов и из социальных сетей, а также производят собственный видеоконтент. Neue Zürcher Zeitung и Tages Anzeiger выпускают собственные передачи, интервью и короткие новостные сюжеты. Видео является эффективным способом привлечения аудитории и рекламодателей. Более того, мультимедийная редакция Tages Anzeiger развивает это направление и исследует возможности производства видео-360 и контента для шлемов виртуальной реальности.

Иногда редакции создают спецпроекты исключительно с использованием видеоконтента. Яркий пример - серия интервью от Tages Anzeiger, в которых представители политических партий в разных кантонах рассказывают о своем вкладе в жизнь сообщества. Смонтированные ролики сопровождаются субтитрами с краткими комментариями. Популярность видео 


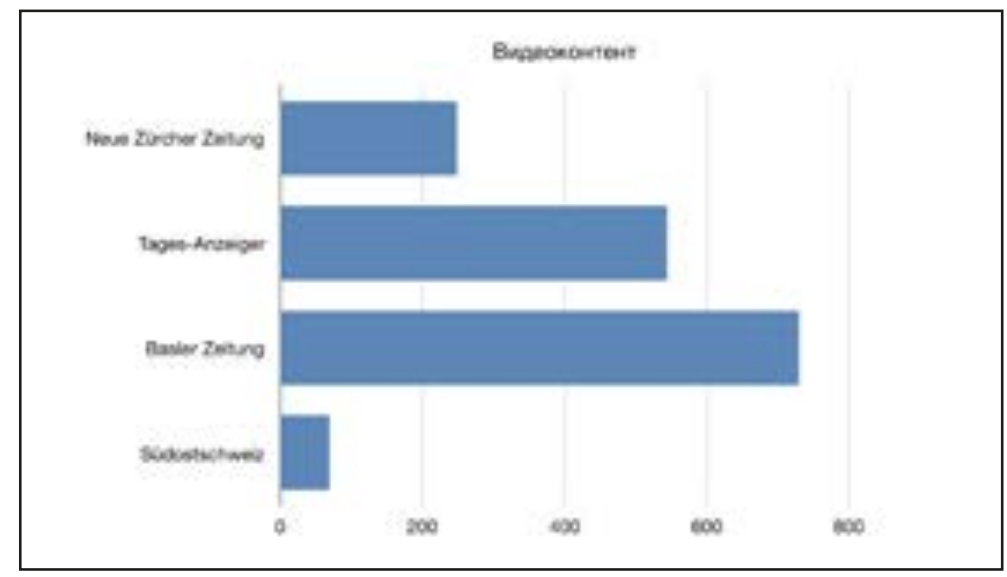

Рисунок 2. Использование видеоконтента изданиями, октябрь 2018 г.

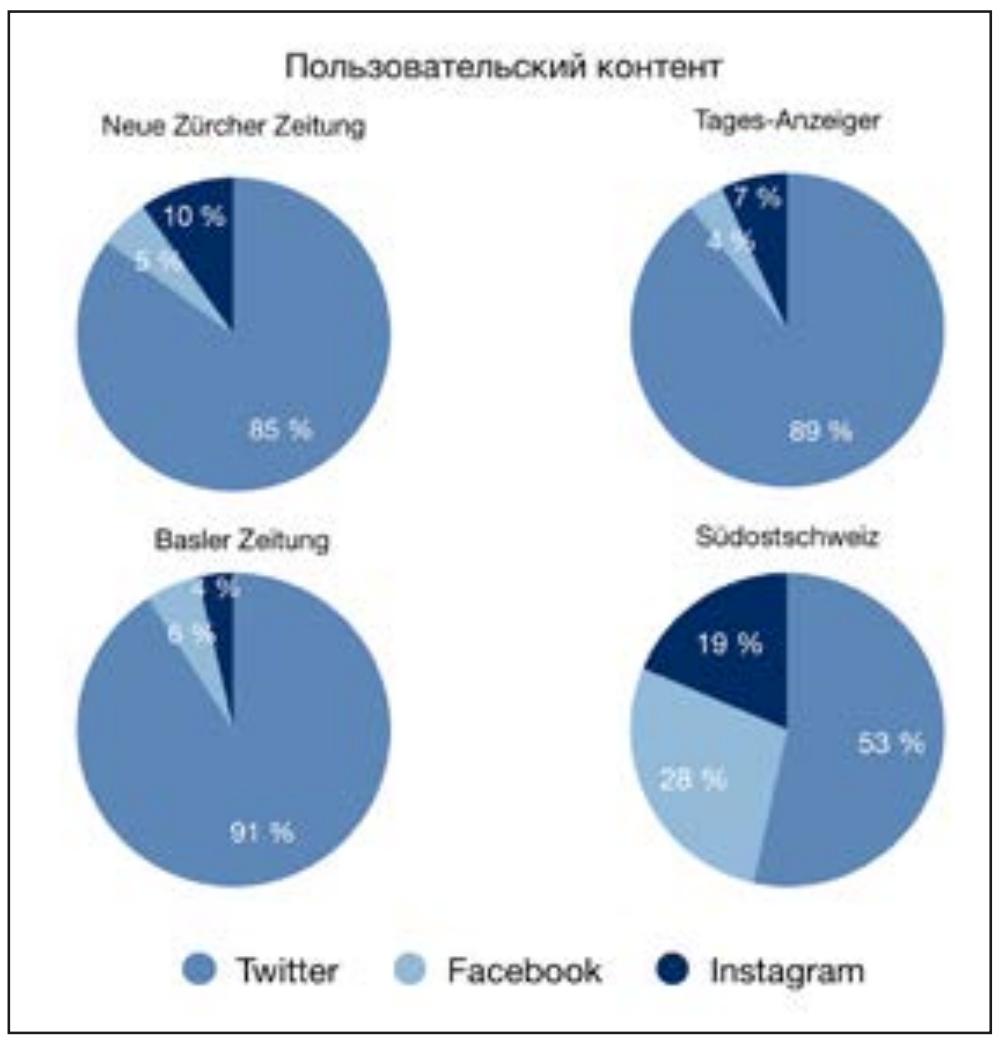

Рисунок 3. Источники пользовательского контента в изданиях, октябрь 2018 г. 
можно объяснить также и распространением информации в социальных сетях например, в Facebook. Процесс подготовки видео очень прост, актуальные материалы присылают в редакцию либо их можно найти на общедоступных платформах, они ярко передают информацию, хорошо воспринимаются пользователями, работают как индивидуальные элементы в рубрике, а также как часть больших мультимедийных материалов.

Несмотря на то, что в публикациях Südostschweiz видеоконтент встречается не так часто, как в других медиа, под этим брендом и на этой платформе свой контент публикуют одноименные радиостанция и телеканал. Они не попадают в общую новостную ленту, но пользователь ежедневно в прямом эфире или в записи может посмотреть новостные программы, прогноз погоды, ток-шоу и другие передачи, производимые телеканалом.

Пользовательский контент. В попытках привлечь аудиторию современные редакции часто обращаются к пользовательскому контенту, они создают площадку, где читатели становятся авторами (см. рис. 3). Пользовательский контент позволяет увеличить интерактивность, дает возможность наладить прямой контакт между журналистами и их аудиторией. Кроме того, это хороший источник информации: фото, видео, текст, иллюстрации, сделанные пользователями, можно свободно обрабатывать и распространять. Смартфоны с видеокамерами есть практически у каждого, а это значит, что любой пользователь - потенциальный производитель контента. Так редакции получают актуальную информацию, интересную аудитории.

Чаще редакции обращаются к Twitter. Это можно объяснить тем, что социальная сеть стала важной частью современной политической культуры. К примеру, материалы с заявлениями Дональда Трампа зачастую сопровождаются его публикациями в со- циальной сети. Реже можно встретить фотографии из Instagram и посты из Facebook. За октябрь 2018 г. Basler Zeitung использовало 189 постов из Twitter, 12 из Facebook и восемь из Instagram.

\section{Заключение}

Использование мультимедийного контента - одна из особенностей перехода СМИ на цифровую платформу. Новая среда определяет конвергентность редакций, объединяя традиции печатной, телевизионной и радиожурналистики, добавляя интерактивность технологических платформ. Но типы используемых мультимедийных элементов меняются от медиа к медиа. Производство качественного визуального контента требует профессионализма от сотрудников, финансовых инвестиций, временных ресурсов, что может позволить себе не каждое СМИ. На примере швейцарских изданий, где территориальные особенности определили локализацию медиа, можно проследить, как разные типы СМИ используют возможности онлайн-платформы и как они адаптируют новые мультимедийные инструменты под свои запросы.

Анализ четырех немецкоязычных медиа позволил выявить факторы, определяющие частоту публикации и качество мультимедийного контента в общественно-политических онлайн-медиа. Швейцарский медиарынок делится на надрегиональный и локальный, аудитория этих медиа, затрагиваемые ими темы, модели финансирования заметно отличаются и отражаются на редакциях. Надрегиональные издания, Tages Anzeiger и Neue Zürcher Zeitung, имея большую аудиторию, устойчивую бизнес-модель и известный бренд, первыми вышли на онлайн-рынок. Neue Zürcher Zeitung - первое СМИ в Швейцарии, сформировавшее отдел цифрового развития и интегрировавшее PayWall. Это позволило им не только дублировать материалы из печатных версий, но и раз- 
рабатывать уникальный онлайн-контент, анализируя запросы аудитории, экспериментируя с разными платформами и типами контента, формировать самостоятельные конвергентные редакции, занимающиеся производством качественного визуального контента. Basler Zeitung, Südostschweiz и другие локальные издания, напротив, работают с запросами аудитории своего региона, балансируя между печатной и онлайн-версией. За октябрь 2018 г. у Neue Zürcher Zeitung вышло в общей сложности 4235 материалов, за этот же месяц издание Tages Anzeiger опубликовало 544 видео, 417 из которых - производство самой редакции. Значительная часть материалов Südostschweiz - новостные заметки, заимствованные у агентства Agentur sda, и интервью, сопровождаемые портретными фотографиями. Тем не менее локальные медиа, работая со своей аудиторией, учитывают ее запросы, создавая универсальную платформу, предлагая разные типы информации и услуг: региональные новости, фильтруемые по индексу, прогноз погоды, местные криминальные сводки.

Ресурсы медиа - определяющий фактор использования конвергентных элементов в публикациях. Аудитория Neue Zürcher Zeitung в разы превышает аудиторию Basler Zeitung. Первое издание опубликовало за октябрь 2018 г. 4235 материалов, второе 2889. Использование оригинальных мультимедийных форматов, таких как аудио или тесты, недоступно небольшим редакциям из-за нехватки ресурсов. Тем не менее существует несколько мультимедийных форматов, распространенных во всех СМИ. Фотографии - самый популярный элемент, который можно найти практически в каждой публикации. Событийные фотографии хорошо иллюстрируют текст, тематические помогают добавить контекст. Специальные сервисы сделали поиск фотографий быстрым и доступным, издания обращаются к фотобанкам информационных агентств и сайтам со стоковыми снимками. Все проанализированные издания отдельно выделяют галереи, создавая профильные разделы сайта, которые иллюстрируют громкие мероприятия и происшествия и используются в публикациях многократно.

Широкое распространение получил и видеоконтент. Зачастую его берут из социальных сетей и стриминговых сервисов. Производство собственного контента менее распространено, так как требует дополнительных профессиональных и финансовых ресурсов. Популярность этого формата меняется в зависимости от СМИ. За октябрь 2018 г. издание Neue Zürcher Zeitung опубликовало 249 видео, из которых 188 заимствованы у YouTube и Facebook, a 61 оригинальные. Чаще всего формат видео использует Basler Zeitung, за анализируемый месяц издание опубликовало 730 видео (617 оригинальных, 104 из YouTube и 9 из Twitter). Südostschweiz в данном случае уникальный пример конвергентного локального медиа, уже после перехода СМИ на онлайн-платформу были созданы одноименные телеканал и радиостанция. Сегодня к ним можно подключиться в прямом эфире или найти записи выпусков на сайте. У телеканала есть собственная редакция с профильными специалистами, занимающимися спортивной, культурной, экономической и другими темами.

Исследование также помогло выявить, как используемые мультимедийные элементы соотносятся с темами, затрагиваемыми СМИ. Надрегиональные издания - Neue Zürcher Zeitung и Tages Anzeiger - концентрируются на национальной и международной повестке, уделяя много внимания темам экономики и политики. Материалы о международных отношениях они зачастую сопровождают статичными или интерактивными картами, экономические данные обычно оформляют в инфографику. За октябрь 2018 г. Neue Zürcher Zeitung опубликовало 519 элементов инфографи- 
ки, Tages Anzeiger - 143. Некоторые материалы могут состоять исключительно из инфографики (например, демонстрировать динамику прибыли из отчетов крупных корпораций). Использование формата таблицы характерно для публикации спортивных новостей.

Таким образом, можно сделать вывод, что все медиа так или иначе адаптировались к особенностям цифровой платформы, используя возможность анализировать свою аудиторию, напрямую вступать в коммуникацию с пользователями. Анализ мультимедийного контента швейцарских медиа показал, что крупные редакции чаще используют возможности цифровой платформы: формируют специализированные редакции, добавляют интерактивные компоненты, работают над крупными мультимедийными проектами. Региональные редакции ограничиваются использованием отдельных мультимедийных элементов, подстраиваясь под запросы своей аудитории.

\section{Примечания}

${ }^{1}$ Auflagenbeglaubigung WEMF/KS, 2018. Режим доступа: https://www. schweizermedien.ch/zahlen-fakten/branchendaten

2 Reuters Institute Digital News Report, 2018. Режим доступа: https://reutersinstitute. politics.ox.ac.uk/sites/default/files/digital-news-report-2018.pdf

${ }^{3}$ Qualität der Medien, 2018. Режим доступа: https://docs.wixstatic.com/ugd/440644_ e544f5b4171c4138a97a6216d05146el.pdf

${ }^{4}$ NET-Metrix AG, 2019. Режим доступа: https://netreport.net-metrix.ch/traffic/

\section{Библиография}

Баранова Е.А. Конвергентная журналистика. Теория и практика: учеб. пособие. М.: Юрайт, 2017.

Вьюгина Д.М. Особенности медиапотребления цифрового поколения России // Медиаскоп. 2017. Вып. 4. Режим доступа: http://www.mediascope.ru/2386

Вырковский А.В., Галкина М.Ю., Колесниченко А.В., Образцова А.Ю. и др. Мультимедийные элементы в современном медиатексте // Медиаскоп. 2017. Вып. 3. Режим доступа: http://www.mediascope.ru/2364

Интернет-СМИ: теория и практика / под ред. М.М. Лукиной. М.: Аспект Пресс, 2013.

Калмыков А.А., Коханова Л.А. Интернет-журналистика: учеб. пособие. М.: ЮНИТИДАНА, 2017.

Пильгун М.А. Мультимедийный текст: особенности функционирования и перспективы развития // Ученые записки Казанск. ун-та. Сер.: Гуманитарные науки. 2015. Т. 157. Кн. 5. С. 192-204.

Уланова М.А. Интернет-журналистика: практическое руководство. М.: Аспект Пресс, 2017.

Хелемендик В.С. Конвергенция как современная форма взаимодействия СМИ // Проблемы современного образования. 2013. № 3. С. 106-123.

Якова Т.С. Медиареальность в контексте социокультурной глокализации (на примере Швейцарии) // Медиаскоп. 2017. Вып. 4. Режим доступа: http://www.mediascope. $\mathrm{ru} / 2385$ 
Якова Т.С. Онлайн-медиа в Швейцарии: тенденции и перспективы // Вестн. Моск. ун-та. Сер. 10: Журналистика. 2013. № 2. С. 94-100.

Blum R. (2014) Lautsprecher und Widersprecher. Ein Ansatz zum Vergleich der Mediensysteme. Front Cover. Köln: Herbert von Halem Verlag.

Hallin D.C., Manchini P. (2004) Comparing Media Systems. Three Models of Media and Politics. Cambridge: Cambridge Univ. Press.

Imhof K. (2006) Mediengesellschaft und Medialisierung. Medien- Kommunikationswissenschaft 54: $191-215$.

Latzer M. (2013) Media Convergence. In: Towse R., Handke Ch. (eds.) Handbook on the Digital Creative Economy. UK, Cheltenham. USA, MA, Northampton: Edward Elgar, pp. 123-134.

Wagner U., Theunert H. (2006) Neue Wege durch die konvergente Medienwelt. München: Reinhard Fischer. 